\author{
Military Technical College \\ Kobry El-Kobbah, \\ Cairo, Egypt.
}

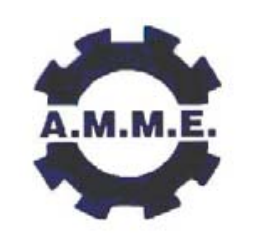

$13^{\text {th }}$ International Conference on Applied Mechanics and Mechanical Engineering.

\title{
OPTIMIZATION TO THE FAILURE OF LAMINATED COMPOSITES WITH DIFFERENT PROVISIONS OF REINFORCEMENT
}

\author{
DELIOU A, BOUROUIS"F. and MILI"F.
}

\begin{abstract}
The objective of this work is to effect a comparative study of the mechanical behavior of composite plates with $[+\theta /-\theta] 3 S$ stacking sequence and subjected to tensile loading. The strength of these various composites is ensured by the choice of the components and the adequate arrangement of fibers. The ultimate strength of regular symmetrical laminates will be predicting by the use of a mathematical approach based on the suitable failure criterion. The different obtained results show a variability of the mechanical behavior according to the more or less pronounced anisotropy degree. They permit to propose hybrids able to improve strength of mat composites by the association of the unidirectional or woven fabric reinforcement. The use of the hybridization technique involves the constitution of the optimal structures and improvement of the mechanical performances of composite materials.
\end{abstract}

\section{KEY WORDS}

Composite materials, Reinforcement, Mechanical behavior and Failure

\footnotetext{
* Researcher, Solar Unit of Development of Equipments, UDES, Tipaza, Algeria.

** Doctor, Dpt. of Mechanical Engineering, Constantine University, Algeria.
} 


\section{Introduction}

The use of composite materials is steadily increasing, especially in aerospace industries which require strong, stiff and light weight structural components [1-3].In addition to the nature of fiber and matrix, the architecture of the reinforcement is the main factor determining the composite mechanical performance. By proper choice of the fiber orientations of the single lamina, composites with optimum properties with regard to the loading requirements can be designed [4-6]. For this reason, we consider the laminated composites with various arrangement of the reinforcement. There have many theoretical and experimental studies on the mechanics of damage in composite structures [7-9]. However, the search of an effective solution to the strength problem of these materials has conducted Cen [10] Shmitt-Thomas [11] to use the hybrid in order to improve the mechanical behavior of composites.

Our work consists of a comparative study of the strength of the E-glass/epoxy plates with different reinforcement types subjected in uniaxial tensile state. This study is effected for regular and symmetrical laminates of six layers $[+\theta /-\theta]_{3 s}$. For each type of reinforcement, a mathematical approach, based on failure criterion, is developed to envisage the ultimate effort which can support the least resistant layer.

\section{Mechanical behavior of symmetric laminates}

The theory of the composite plates is different from that of a traditional material because of existence of coupling between bending and extension. According to the Kirchhoff hypothesis for plates [12].the laminate is presumed to consist of perfectly bonded laminate. The bonds are presumed to be infinitesimally thin as well nonshear-deformable. Moreover, the displacements are continuous across lamina boundaries so that no lamina can slip relative to another. The laminated composite, working in membrane is subjected to force in the plan per unit of length (width) of the cross section of the laminate. The membrane efforts are obtained by integration of the stresses in each layer through the laminate thickness $h$. the distribution of stresses is continuous in a layer but discontinuous of a layer to another. Thus the membrane efforts will be expressed by:

$$
\left\{\begin{array}{l}
N_{x} \\
N_{y} \\
N_{x y}
\end{array}\right\}=\sum_{k=1}^{N} \int_{z_{k-1}}^{z_{k}}\left\{\begin{array}{l}
\sigma_{x} \\
\sigma_{y} \\
\tau_{x y}
\end{array}\right\}_{k} d z
$$

$z_{k}$ and $z_{k-1}$ are respectively the coordinates of the $k^{\text {th }}$ and $(k-1)^{\text {th }}$ layer in the perpendicular direction to the laminate. $\mathrm{N}$ represents the total number of layers. The behavior law of the laminates, that are symmetric in both geometry and material properties about the middle surface, is described by:

$$
\left\{\begin{array}{l}
\mathrm{N}_{\mathrm{x}} \\
\mathrm{N}_{\mathrm{y}} \\
\mathrm{N}_{\mathrm{xy}}
\end{array}\right\}=\left[\begin{array}{lll}
\mathrm{A}_{11} & \mathrm{~A}_{12} & \mathrm{~A}_{16} \\
\mathrm{~A}_{12} & \mathrm{~A}_{22} & \mathrm{~A}_{26} \\
\mathrm{~A}_{16} & \mathrm{~A}_{26} & \mathrm{~A}_{66}
\end{array}\right]\left\{\begin{array}{l}
\varepsilon_{\mathrm{x}}^{\mathrm{o}} \\
\varepsilon_{\mathrm{y}}^{\mathrm{o}} \\
\gamma_{\mathrm{xy}}^{\mathrm{o}}
\end{array}\right\}
$$

in which the extensional stiffnesses rigidities $\mathrm{A}_{\mathrm{ij}}$ are obtained like: 


$$
A_{i j}=\frac{h}{N} \sum_{k=1}^{N}\left(\overline{Q_{i j}}\right)_{k}
$$

\section{Failure mathematical modeling of the composites}

The mechanical loads applied to the composite structures cause various types of degradation such as cracking of the resin, interfacial decoherence, breakage fiber and delamination between the layers. The macromechanical approach study of the strength to the composite material failure consists of the search of a criterion allowing establishing the final composite material strength according to its reinforcement type. The Von Mises criterion relates to isotropic materials working in the elastic range [13].It postulates that the material resists in a state of isotropic stresses, but plasticizes itself when the energy of distortion per unit of volume reaches a critical point:

$$
\frac{1}{\sigma_{0}^{2}}\left[\left(\sigma_{1}-\sigma_{2}\right)^{2}+\left(\sigma_{3}-\sigma_{1}\right)^{2}+\left(\sigma_{2}-\sigma_{3}\right)^{2}+\left(\tau_{12}^{2}+\tau_{23}^{2}+\tau_{31}^{2}\right)\right] \leq 1
$$

$\sigma_{0}$ is the yield stress obtained during a compression or tensile test.

The Tsai-Hill criterion is an energy criterion of Von Mises [14].Because of its easy use, it was extrapolated by Hill for anisotropic materials by introducing into the preceding inequality the anisotropy rate whose each term is equilibrated:

$$
\left(\frac{\sigma_{1}}{\mathrm{X}}\right)^{2}+\left(\frac{\sigma_{2}}{\mathrm{Y}}\right)^{2}-\frac{\sigma_{1} \sigma_{2}}{\mathrm{X}^{2}}+\left(\frac{\tau_{12}}{\mathrm{~S} 1}\right)^{2} \leq 1
$$

$\mathrm{X}$ and $\mathrm{Y}$ are respectively the ultimate longitudinal and transversal strength. $\mathrm{SI}$ is the ultimate shear strength.

The Fisher criterion is applied for orthotropic materials. It is given on the basis of Norris and Fisher analysis [15]. They suppose that the point $\sigma_{1}=P, \sigma_{2}=-P$ and $\tau_{12}=0$ are on the failure surface. The ultimate stress $P$ is that which limits the elastic distortion energy.

$$
\left(\frac{\sigma_{1}}{\mathrm{X}}\right)^{2}+\left(\frac{\sigma_{2}}{\mathrm{Y}}\right)^{2}-\frac{\mathrm{k}}{\mathrm{XY}} \sigma_{1}^{2} \sigma_{2}^{2}+\left(\frac{\tau_{12}}{\mathrm{Sl}}\right)^{2} \leq 1
$$

with: $\quad k=\frac{E_{1}\left(1+v_{21}\right)+E_{2}\left(1+v_{12}\right)}{4 E_{1} E_{2}\left(1+v_{21}\right)\left(1+v_{12}\right)}$

$E_{1}$ and $E_{2}$ are the Young's moduli in the orthotropic directions. $v_{12}$ and $v_{21}$ are the Poisson's ratios of the material. $\mathrm{G}_{12}$ is the in-plane shear modulus of the lamina.

\section{Results and discussions}

The E-glass/epoxy is the considered composite material in this study. It is presented according to the volume fraction of fibers $V_{f}$ and the reinforcement type (unidirectional, woven fabric and mat composite). The six layers constituting the laminates are alternated between $+\theta$ and $-\theta$ and are symmetrically disposed about the middle surface. Strengths and stiffnesses of the three different selected fiber materials are illustrated in table 1.

From Fig. 1 which represents the uniaxial limit strength $N_{x}$ of the three various composites versus the angle $\theta$, we notice a fast degradation of the force resultant of the unidirectional reinforcement material each time that it was approached to $90^{\circ}$ 
orientation (Fig. 1a). Such a composite presents three damage zones. The first corresponds to the fibers tensile failure. Zone III corresponds to the ruin of the material by the epoxy resin shearing in a parallel direction of the interior layer fibers. As the $\theta$ angle approaches $90^{\circ}$, the failure mode changes towards a resin tensile failure. On the other hand, the material with woven fibers takes a symmetric form about the angle $45^{\circ}$ (Fig. 1b). The variation of the ultimate tensile effort according to the fibers orientation presents a decrease of the material strength from $0^{\circ}$ to $45^{\circ}$. For this reason, it is the epoxy matrix of the interior layers which is responsible for the failure of the material. When the reinforcement is mat, the composite behaves like an isotropic material.

For each reinforcement type of the laminated composite plates, it is represented in Figure 2 the failure envelopes. They permit to determine, according to a suitable strength criterion, the surface limits where it is possible to apply stresses tensor without risk to have its failure. It was noticed that to the shear stress $\tau_{12}=0$, the failure envelopes take some elliptic shapes. Moreover, the strong strength of the composites fabrics in the two directions, chains and weaves, permits to obtain surfaces more extended.

The realization of hybrid materials is in the aim of having better properties. For this reason, the unidirectional reinforcement layers, known by their height mechanical strength in the longitudinal direction, are associated with the mat fibers reinforced layers. It is showed on the Figures $3 a$ and $3 b$ the improvement of the (UD/Mat) hybrid laminate strength.

When the number of unidirectional reinforcement layers increases, hybrids become more resistant and less anisotropic. Moreover, the figures $3 \mathrm{c}$ and $3 \mathrm{~d}$ show that the association of the woven fabric layers with mat fibers involves the improvement of the breaking strength of the (Woven fabric/Mat) hybrid laminates. In this case, it is the epoxy matrix of the outside layers with woven reinforcement that first tensile fail.

\section{Conclusions}

The best choice of the composite material components and adequate arrangement of fibers in the matrix permit to get a more resistant laminate. In this way, it is possible to modify the anisotropy degree of material according to the nature of the used composite from the point of view its reinforcement, volume fraction of fibers and orientation of the layers. The hybridization technique permits to solve the strength problem of the mat composites to the various requests. Their association to the unidirectional or woven fibers-reinforced layers involves an improvement of the mechanical behavior of all composite material.

\section{References}

[1] Gentz, M., Benedikt, B., Sutter, J. K. and Kumosa, M., 2004, Residual stresses in unidirectional graphite fiber/polyimide composites as a function of aging, Composites Science and Technology, 64, 1671-1677.

[2] Lee, N. J. and Jang, J., The use of a mixed coupling agent system to improve the performance of polypropylene-based composites reinforced with short-glassfibre mat, Composites Science and Technology, 57, 1559-1569,(1998) 
[3] Chiang, M. Y. and He, J., An analytical assessment of using the losipescu shear test for hybrid composites, Composites Part B: Engineering, 33, 461470,(2002)

[4] Brandt, J., Drechslef, k. and Arendtsb, F.J., Mechanical performance of composites based on various three -dimensional woven -fibre performs, Composites Science and Technology, 381-386,(1996)

[5] Zhen, W., Ronggeng, C. and Wanji, C., Refined laminated composite plate element based on global-local higher-order shear deformation theory, Composite structures, 135-152,(2005)

[6] Dong, C. P. and Dai, G. L., Through-thickness compressive strength of carbonphenolic woven composites, Composite structures, 403-412.

[7] Attia, A. N., 2001, New phase reinforcement for composite, Materials \& Design, $22,459-466,(2004)$

[8] Verrey, J., Winkler, Y., Michaud, V. and Manson, J. A. E., 2005, Interlaminar fracture toughness improvement in composites with hyperbranched polymer modified resin. Composites Science and Technology, 1527-1536.

[9] Masarati, P. and Ghiringhelli, G L., Characterization of anisotropic, nonhomogeneous plates with piezoelectric inclusions, Computers \& structures, 1171-1190,(2005)

[10] Cen, S., Long, Y. and Yao, Z., A new hybrid-enhanced displacement-based element for the analysis of laminated composite plates, Computers \& Structures, 80, 819-833,(2002)

[11] Schmitt-Thomas, K. G, Yang, Z. G. and Malke, R., Failure behavior and performance analysis of hybrid-fiber reinforced PAEK composites at high temperature, Composites Science and Technology, 58, 1509-1518,(1997)

[12] Jones, R.M., Mechanics of composite materials, Macromechanical Behavior of a Laminate, ed., John Wiley \& Sons, New York, 147-237,(1979)

[13] Bigoni, D. and Piccolroaz, A., 2004, Yield criteria for quasibrittle and frictional materials, International Journal of Solids and Structures, 41, 2855-2878.

[14] Gillespie, J. E., Gama, B. A., Cichanowski, C. E. and Xiao, J. R., Interlaminar shear strength of plain weave S2-glass/SC79 composites subjected to out-ofplane high strain rate compressive loadings, Composites Science and Technology, 1891-1908,(2005)

[15] Yang; G., xperimental investigation of strength criteria for S-glass, E-glass and graphite fiber composite plate, Theoretical and Applied Fracture Mechanics, 20, 59-66,(1994)

[16] Thinh, T.I., Contribution à l'étude expérimentale du comportement mécanique et de l'endommagement d'un composite stratifié à renfort tissu, Thèse de doctorat, Ecole nationale supérieure d'hydraulique et de mécanique, Grenoble,(1991) 
Table 1. Mechanical properties of E-glass/epoxy lamina with different reinforcement types [16].

\begin{tabular}{|c|c|c|c|c|c|c|c|}
\hline & $\begin{array}{c}\mathrm{E}_{1} \\
(\mathrm{Gpa})\end{array}$ & $\begin{array}{c}\mathrm{E}_{2} \\
(\mathrm{Gpa})\end{array}$ & $\begin{array}{c}\mathrm{v}_{12} \\
-\end{array}$ & $\begin{array}{c}\mathrm{G}_{12} \\
(\mathrm{Gpa})\end{array}$ & $\begin{array}{c}\mathrm{X} \\
(\mathrm{Mpa})\end{array}$ & $\begin{array}{c}\mathrm{Y} \\
(\mathrm{Mpa})\end{array}$ & $\begin{array}{c}\mathrm{SI} \\
(\mathrm{Mpa})\end{array}$ \\
\hline UD & 45 & 12 & 0.3 & 4.5 & 1250 & 35 & 63 \\
\hline $\begin{array}{c}\text { Woven } \\
\text { fabric }\end{array}$ & 20.9 & 20.6 & $\begin{array}{c}0.1 \\
4\end{array}$ & 5.05 & 460 & 420 & 55 \\
\hline Mat & 14 & 14 & 0.3 & 5.38 & 140 & 140 & 70 \\
\hline
\end{tabular}

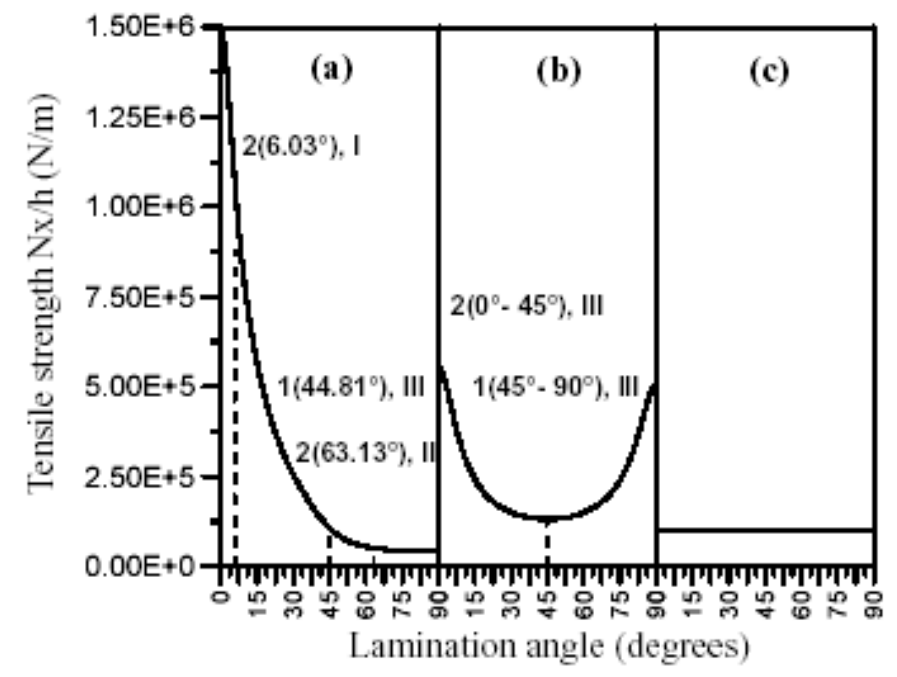

Fig. 1 Variation of ultimate tensile strength of the $[+\theta /-\theta]_{3}$ laminates with angle orientation of the composites (a) unidirectional, (b) woven fabric and (c) mat. 


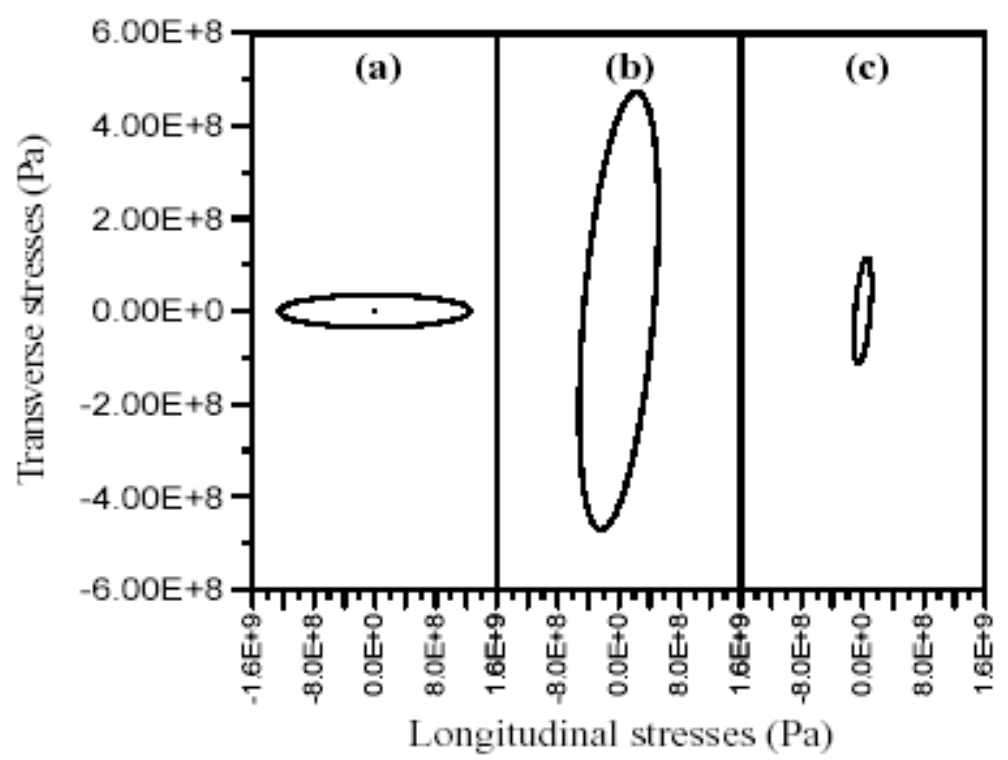

Fig. 2 Failure envelopes of the first deformed layers obtained for $\tau 12=0$ in the case of the $[+\theta /-\theta] 3 S$ laminate with reinforcement (a) unidirectional, (b) woven fabric and (c) mat composite

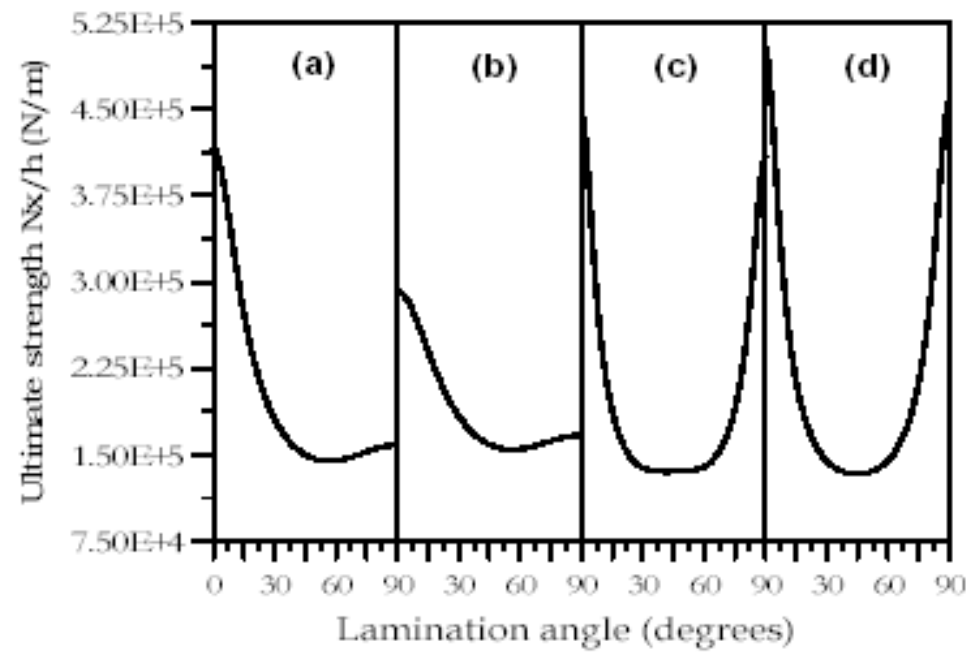

Fig. 3 Variation of ultimate strengths versus lamination angle of laminated hybrids (a) UD/Mat, (b) Mat/UD, (c) Mat/woven fabric and (d) woven fabric/Mat. 